\title{
ECONOMIC GROWTH V.S. ECONOMIC DEVELOPMENT - COMPLEMENTARY INDICATORS
}

\author{
Vera Karadjova ${ }^{1}$ \\ Snezhana Dichevska ${ }^{2}$
}

Received: November 21, 2018 / Revised: January 25, 2019/ Accepted: March 16, 2019

(C) Association of Economists and Managers of the Balkans, 2019

\begin{abstract}
The paper deals with a topic relating to the economic growth, development and general welfare of a national economy, a wider region, or even the entire world, through indicators that differentiate growth from development. It is a complex subject that contains numerous aspects of the life of a community in a certain space, which, because of its complexity, cannot be limited exclusively to economic aspects, so because of that cannot be limited exclusively to economic or monetary indicators. Life in a community besides the economic includes also legal, sociological, philosophical, psychological and other aspects, from which it logically results that measuring the development and welfare is a complex process that can hardly be limited to one indicator. In that sense, the paper addresses issues relating to production, distribution, fairness and equality, employment, unemployment, poverty, productivity, economic stability, sustainable development, human development, a sense of well-being and happiness, etc., in the direction of the thesis for the use of complementary development indicators. The complexity of the process of harmonizing the numerous indicators is further complicated by the need to calculate the degree of their mutual correlation, especially if it concerns divergent indicators or indicators that are mutually exclusive or have a negative correlation.
\end{abstract}

The issue of welfare has been the subject of economic science interest since its very beginnings, even from the time of the first ancient thinkers when it was not singled out as an independent science, through the utopians, to contemporary economic thought. The economic operation and the rational use of limited resources in order to meet unlimited human needs is the heart of the economy. The basic indicator used to measure economic growth is undoubtedly the GDP and GDP per capita. But one has to take into account the distinction between quantitative growth and qualitative development, whereby GDP is an indicator of growth. Development is a broader concept that covers growth, but also technological and any other kind of advancement of the social community. Development as a qualitative feature means the advancement of the qualitative

This paper was presented at the Second International Scientific Conference on IT, Tourism, Economics, Management and Agriculture - ITEMA 2018 - November 8, 2018, Graz, Austria, www.itema-conference.com

\footnotetext{
Vera Karadjova

verakaradzo@yahoo.com
}

1 Faculty of Tourism and Hospitality - Ohrid, Kej Makedonija 95, Ohrid, North Macedonia

2 Faculty of Tourism and Hospitality - Ohrid, Kej Makedonija 95, Ohrid, North Macedonia 
characteristics of society and the well-being of individuals, and the well-being is not only the increase of GDP, but the subjective sense of the people in the community that they live better, a sense of improving the quality of life. Growth and development together make the progress of the community. In this sense the paper elaborates just a few indicators of growth and development that are used parallel, such as GDP, Human Development Index, and the World Happiness index, that do not exclude each other and whose interwoven use gives a fuller picture of growth and development although the ranking of countries around the world according to one of these indicators may be quite different with respect to the ranking according to the other indicator. This only confirms the thesis of the need for a more comprehensive analysis of the analyzed issues and suggestions for a more comprehensive indicator that would be a complementary set of several alternative and complementary ones that would eliminate the shortcomings of its constituent parts, thereby obtaining a relevant indicator of economic development and welfare, without any intention to propose a concrete solution.

Keywords: economic growth, economic development, welfare, prosperity, GDP, Human Development Index, the World Happiness score

\section{JEL Classification E1 $\cdot 01 \cdot 04$}




\section{INTRODUCTION}

The distinction between terms growth and development is not only semantic, but also have a deeper substantive meaning. The level of economic growth is measured by generally accepted indicators in the world, such as gross domestic product (GDP) and gross domestic product per capita. For the purposes of more precise quantification of growth, and in the direction of determining the development, this indicator is complemented by other economic and social indicators such as the degree of industrialization, the level of education, health and social protection, the length of life, mortality, infant mortality, and a range of other indicators. It is in this direction that specific reports on ,human development" are developed within the United Nations (UN), i.e. for overall economic and social development of the community, and not only for the economic development of the country. In addition to economic, these reports also take into account other indicators that refer to health, social, cultural, educational and other aspects of life, up to environmental protection. Moreover, data show that some countries which are on the top of the list of countries according to gross domestic product are lower on the list of aggregate human development index (HDI), that is, according to social indicators or vice versa. The generally accepted principle that economic development is not an end in itself, but should be in the direction of overall human development, still encounters difficulties in its application. Besides these two indicators of growth or development, there are other alternative attempts for complementary indicators of well-being. In this sense is the indicator World happiness score, which is published annually in the World Happiness Report as an annual publication of the United Nations Sustainable Development Solutions Network (SDSN). It contains rankings of national happiness and analysis of the data from various perspectives. SDSN engages scientists, engineers, business and civil society leaders, and development practitioners for evidence based problem solving. It promotes solutions initiatives that demonstrate the potential of technical and business innovation to support sustainable development. Although this indicator is based on the UN General Assembly resolution 65/309 Happiness: Towards a Holistic Definition of Development adopted on 19 July 2011, it is clearly stated that The World Happiness Report was written by a group of independent experts acting in their personal capacities. Any views expressed in the report do not necessarily reflect the views of any organization, agency or program of the United Nations.

The intent of this paper is to determine the correlation between the most commonly used indicators for growth and development on the example of the 20 highest ranked countries in the world based on the latest published data (2018), and in the direction of setting up a future model for quantification of growth and development, which certainly exceeds the space of paper of this scope and kind.

\section{ECONOMIC GROWTH V.S. ECONOMIC DEVELOPMENT - BASIC INDICATORS FOR GROWTH AND DEVELOPMENT}

The basic indicator for production quantification in all countries in the world and according to which they are classified in reference to the development level is gross domestic product (GDP) and gross domestic product per capita (GDP per capita). GDP is considered the "world's most powerful statistical indicator of national development and progress" (Lepenies, P. \& Gaines, J., 2016). Gross Domestic Product (GDP) is a monetary measure of the market value of all the final goods and services produced in a period of time, often annually or quarterly. So, GDP is the total market value of all final goods and services produced in a country in a given year. The OECD defines GDP as "an aggregate measure of production equal to the sum of the gross values added of all resident and institutional units engaged in production (plus any taxes, and minus any subsidies, on products not included in the value of their outputs)" (OECD, SNA 1.128 and 2.173-2.174). An 
IMF publication states that "GDP measures the monetary value of final goods and services - that are bought by the final user - produced in a country in a given period of time (say a quarter or a year)" (Callen, 2017). Total GDP can also be broken down into the contribution of each industry or sector of the economy (Dawson, G., 2006, 205). In the literature there is also a distinction between gross domestic product (GDP) and gross national product (GNP), which actually have the same meaning, with the difference that GNP includes also the economic transactions with abroad, i.e. net exports. Thus, GNP represents the amount of the market value of all material goods and services in the final consumption that are produced, sold and spent in the country's economy for one year, including the economic transactions with abroad, i.e. net exports (Mojsoski, V. \& Karadjova, V., 2002, 359). Nominal GDP estimates are commonly used to determine the economic performance of a whole country or region, and to make international comparisons. The ratio of GDP to the total population of the region is the per capita GDP. But, nominal GDP per capita does not, however, reflect differences in the cost of living and the inflation rates of the countries; therefore using a basis of GDP per capita at purchasing power parity (PPP) is arguably more useful when comparing differences in living standards between nations. In Nominal method, market exchange rates are used for conversion. To make meaningful comparison, PPP is used to compare economies and incomes of people by adjusting differences in prices in different countries. But such exclusive expression of growth only through monetary indicators minimizes the impact of some other factors. Thus determined GDP with all the adjustments made (in terms of GDP per capita, PPP, etc.) although is a measure of production, however, methodologically cannot include certain parts of the total production that remain outside of it, for example GDP does not include non-market products and services (production for own needs, work at home, care for family and children, etc.), volunteer work, black economy, gray economy (can be included only through assessments), disasters and accidents increase GDP and this does not mean improving the well-being. In this sense, some other complementary indicators show the prosperity and general human progress.

The Human Development Index (HDI) was created to emphasize that people and their capabilities should be the ultimate criteria for assessing the development of a country, not economic growth alone. The HDI can also be used to question national policy choices, asking how two countries with the same level of GNI per capita can end up with different human development outcomes. These contrasts can stimulate debate about government policy priorities. The Human Development Index (HDI) is a summary measure of average achievement in key dimensions of human development: a long and healthy life, being knowledgeable and have a decent standard of living. The HDI is the geometric mean of normalized indices for each of the three dimensions (UNDP, Human Development Reports, 2018). It is a standard way of calculating human development in a country, a concept that according to UNDP should extend people's preferences and give them greater opportunities for education, health care, income, employment, etc. The concept of HDI was developed in 1990 by Pakistani economist Mahbub ul Haq and a group of development economists including Paul Streeten, Frances Stewart, Gustav Ranis, Keith Griffin, Farhan C.M. Sudhir Anand, and Meghnad Desai. Nobel laureate Amartya Sen utilized Haq's work in his own work on human capabilities (UNDP, The Human Development concept, 2010).

Since 1990, it has been used by the United Nations in its Annual Human Development Report. The HDI combines three factors:

- Life expectancy at birth, as an indicator of the health and longevity of the population;

- Knowledge and education, measured through literacy of adults (as 2/3 of the weight) and total enrollment in primary, secondary and tertiary education (as $1 / 3$ of weight);

- The standard of living, expressed in terms of a natural logarithm of GDP per capita in USD. 
The value of HDI can range from 0 to 1 . Values below 0.5 are considered to represent a low level of development of the country. All countries with HDI below 0.5 are in Africa. Countries with HDI of 0.8 and more are considered to be developed. In this group are all developed countries of North America, Western Europe, East Asia, and some developing countries in Eastern Europe. Seven countries, including Macedonia, have crossed into this group in 2007. A fuller picture of a country's level of human development requires analysis of other indicators and information presented in the statistical annex of the report.
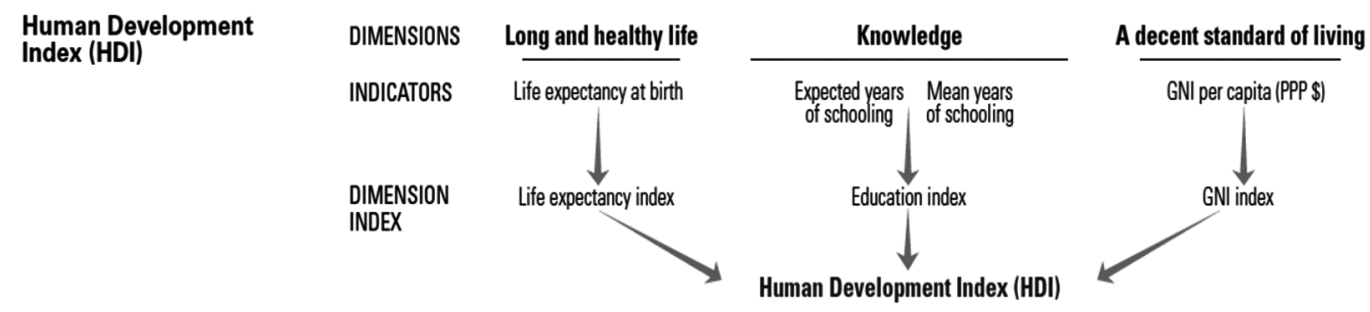

Figure 1: Key elements of the HDI (UNDP, Human Development Reports, 2018)

World happiness score is another indicator for development which is in use from 2012 when first World Happiness Report was released (April 1, 2012). In the reports, experts in fields including economics, psychology, survey analysis, and national statistics, describe how measurements of well-being can be used effectively to assess the progress of nations, and other topics. Each report is organized by chapters that delve deeper into issues relating to happiness, including mental illness, the objective benefits of happiness, the importance of ethics, policy implications, and links with the Organization for Economic Co-operation and Development's (OECD) approach to measuring subjective well-being and other international and national efforts. Data is collected from people in over 150 countries (156 in 2018 Report). Each variable measured reveals a populated-weighted average score on a scale running from 0 to 10 that is tracked over time and compared against other countries. These variables currently include: real GDP per capita, social support, healthy life expectancy, freedom to make life choices, generosity, and perceptions of corruption. However, this score is also subject to criticism regarding the three basic issues: Metrics, Methodology, and Philosophical concerns.

\section{NEED FOR COMPLEMENTARY INDICATORS}

The distinction between growth and development, as well as the existence and parallel use of several indicators that quantify one, or the other category, go in favor of the need to develop a more comprehensive indicator that would overcome the weaknesses of the already used ones.

Table No. 1 gives an overview only to the 10 first ranked countries in the world according to official reports for 2018. In conditions of limited space for the full list of countries being analyzed (according to GDP - 193; according to the HDI - 189; and according to HS - 156), this review of the 10 first - ranked shows vividly enough the diversity of the countries that occupy the first places according to the different indicator. In this regard, the following is an overview of the mutual correlation between the three indicators mentioned above, using the Pearson Correlation Coefficient. For greater reliability of the results, the analysis was made using a data sample for the 20 highest ranked countries. 
Table 1: First 10 in 2018 according to the appropriate indicator

\begin{tabular}{|c|c|c|}
\hline GDP Nominal share $-2018^{*}$ & $\begin{array}{c}\text { Human development index - } \\
\text { HDI rank } 2018^{* * *}\end{array}$ & Happiness score $2018^{* * * *}$ \\
\hline United States & Norway & Finland \\
\hline China & Switzerland & Norway \\
\hline Japan & Australia & Denmark \\
\hline Germany & Ireland & Iceland \\
\hline United Kingdom & Germany & Switzerland \\
\hline France & Iceland & Netherlands \\
\hline India & Hong Kong, China (SAR) & Canada \\
\hline Italy & Sweden & New Zealand \\
\hline Brazil & Singapore & Sweden \\
\hline Canada & Netherlands & Australia \\
\hline
\end{tabular}

* $\quad$ (List of Countries by GDP (Nominal), 2018)

** (UNDP, Latest Human Development Index (HDI) Ranking, 2018)

*** $\quad$ (World Happiness Report, 2018)

\section{Correlation Coefficient (HDI/Happiness score)}

$\mathrm{X}$ Values - HDI - best 20 in 2018

Y Values - Happiness score 2018 - corresponding countries

\begin{tabular}{c|c}
\hline X Values & Y Values \\
\hline 0.953 & 7.594 \\
0.944 & 7.487 \\
0.939 & 7.272 \\
0.938 & 6.977 \\
0.936 & 6.965 \\
0.935 & 7.495 \\
0.933 & 6.441 \\
0.933 & 7.314 \\
0.932 & 6.343 \\
0.931 & 7.441 \\
0.929 & 7.555 \\
0.926 & 7.328 \\
0.924 & 6.886 \\
0.922 & 6.814 \\
0.92 & 7.632 \\
0.917 & 7.324 \\
0.916 & 6.927 \\
0.916 & 5.915 \\
0.909 & 7.139 \\
0.908 & 6.910 \\
\hline
\end{tabular}




\begin{tabular}{|c|c|c|c|c|}
\hline $\mathrm{X}-\mathrm{M}_{\mathrm{x}}$ & $\mathrm{Y}-\mathrm{M}_{\mathrm{y}}$ & $\left(\mathrm{X}-\mathrm{M}_{\mathrm{x}}\right)^{2}$ & $\left(\mathrm{Y}-\mathrm{M}_{\mathrm{y}}\right)^{2}$ & $\left(\mathrm{X}-\mathrm{M}_{\mathrm{x}}\right)\left(\mathrm{Y}-\mathrm{M}_{\mathrm{y}}\right)$ \\
\hline 0.025 & 0.506 & 0.001 & 0.256 & 0.013 \\
0.016 & 0.399 & 0.000 & 0.159 & 0.006 \\
0.011 & 0.184 & 0.000 & 0.034 & 0.002 \\
0.010 & -0.111 & 0.000 & 0.012 & -0.001 \\
0.008 & -0.123 & 0.000 & 0.015 & -0.001 \\
0.007 & 0.407 & 0.000 & 0.166 & 0.003 \\
0.005 & -0.647 & 0.000 & 0.419 & -0.003 \\
0.005 & 0.226 & 0.000 & 0.051 & 0.001 \\
0.004 & -0.745 & 0.000 & 0.555 & -0.003 \\
0.003 & 0.353 & 0.000 & 0.125 & 0.001 \\
0.001 & 0.467 & 0.000 & 0.218 & 0.000 \\
-0.002 & 0.240 & 0.000 & 0.058 & 0.000 \\
-0.004 & -0.202 & 0.000 & 0.041 & 0.001 \\
-0.006 & -0.274 & 0.000 & 0.075 & 0.002 \\
-0.008 & 0.544 & 0.000 & 0.296 & -0.004 \\
-0.011 & 0.236 & 0.000 & 0.056 & -0.003 \\
-0.012 & -0.161 & 0.000 & 0.026 & 0.002 \\
-0.012 & -1.173 & 0.000 & 1.376 & 0.014 \\
-0.019 & 0.051 & 0.000 & 0.003 & -0.001 \\
-0.020 & -0.178 & 0.000 & 0.032 & 0.004 \\
$\mathrm{Mx} 0.928$ & $\mathrm{My:} \mathrm{7.088}$ & Sum: 0.003 & Sum: 3.971 & Sum: 0.032 \\
\hline
\end{tabular}

\begin{tabular}{|c|c|}
\hline  & $\begin{array}{l}\text { Key } \\
X: X \text { Values } \\
Y: \text { Y Values } \\
M_{x}: \text { Mean of X Values } \\
M_{y}: \text { Mean of Y Values } \\
X-M_{\mathrm{x}} \& Y-M_{y}: \text { Deviation scores } \\
\left(X-M_{x}\right)^{2} \&\left(Y-M_{y}\right)^{2}: \text { Deviation Squared } \\
\left(X-M_{x}\right)\left(Y-M_{y}\right): \text { Product of Deviation Scores }\end{array}$ \\
\hline
\end{tabular}

The value of $\mathrm{R}$ is 0.3149 .

Although technically this is a positive correlation, the relationship between the variables is weak (the nearer the value is to zero, the weaker the relationship).

The value of $\mathrm{R}^{2}$, the coefficient of determination, is 0.0992 . 


\section{Correlation Coefficient (HDI/GDP share)}

$\mathrm{X}$ Values - HDI - best 20 in 2018

Y Values - GDP share 2018 (List of Countries by GDP (Nominal), 2018) (Nominal (billions of \$) corresponding countries (International Monetary Fund, World Economic Outlook, 2018)

\begin{tabular}{c|c}
\hline X Values & Y Values \\
\hline 0.953 & 0.331 \\
0.944 & 0.507 \\
0.939 & 0.423 \\
0.938 & 0.0333 \\
0.936 & 0.848 \\
0.935 & 1.08 \\
0.933 & 2.06 \\
0.933 & 0.252 \\
0.932 & 0.687 \\
0.931 & 1.71 \\
0.929 & 0.427 \\
0.926 & 0.546 \\
0.924 & 0.0700 \\
0.922 & 0.440 \\
0.92 & 4.81 \\
0.917 & 0.643 \\
0.916 & 0.0828 \\
0.916 & 23.3 \\
0.909 & 3.36 \\
0.908 & 0.471 \\
\hline
\end{tabular}

\begin{tabular}{|c|c|c|c|c|}
\hline $\mathrm{X}-\mathrm{M}_{\mathrm{x}}$ & $\mathrm{Y}-\mathrm{M}_{\mathrm{y}}$ & $\left(\mathrm{X}-\mathrm{M}_{\mathrm{x}}\right)^{2}$ & $\left(\mathrm{Y}-\mathrm{M}_{\mathrm{y}}\right)^{2}$ & $\left(\mathrm{X}-\mathrm{M}_{\mathrm{x}}\right)\left(\mathrm{Y}-\mathrm{M}_{\mathrm{y}}\right)$ \\
\hline 0.025 & -1.773 & 0.001 & 3.144 & -0.044 \\
0.016 & -1.597 & 0.000 & 2.551 & -0.025 \\
0.011 & -1.681 & 0.000 & 2.826 & -0.018 \\
0.010 & -2.071 & 0.000 & 4.288 & -0.021 \\
0.008 & -1.256 & 0.000 & 1.578 & -0.010 \\
0.007 & -1.024 & 0.000 & 1.049 & -0.007 \\
0.005 & -0.044 & 0.000 & 0.002 & 0.000 \\
0.005 & -1.852 & 0.000 & 3.430 & -0.009 \\
0.004 & -1.417 & 0.000 & 2.008 & -0.006 \\
0.003 & -0.394 & 0.000 & 0.155 & -0.001 \\
0.001 & -1.677 & 0.000 & 2.813 & -0.002 \\
-0.002 & -1.558 & 0.000 & 2.428 & 0.003 \\
-0.004 & -2.034 & 0.000 & 4.137 & 0.008 \\
-0.006 & -1.664 & 0.000 & 2.769 & 0.010 \\
-0.008 & 2.706 & 0.000 & 7.322 & -0.022 \\
-0.011 & -1.461 & 0.000 & 2.135 & 0.016 \\
-0.012 & -2.021 & 0.000 & 4.085 & 0.024 \\
-0.012 & 21.196 & 0.000 & 449.268 & -0.255 \\
-0.019 & 1.256 & 0.000 & 1.577 & -0.024 \\
-0.020 & -1.633 & 0.000 & 2.667 & 0.033 \\
$\mathrm{Mx}: 0.928$ & $\mathrm{My:} 2.104$ & Sum: 0.003 & Sum: 500.231 & Sum: -0.350 \\
\hline
\end{tabular}




\begin{tabular}{|l|l|}
\hline Result Details \& Calculation & Key \\
$X$ Values & $X:$ X Values \\
$\sum=18.561$ & $Y$ : Values \\
Mean $=0.928$ & $M_{x}:$ Mean of X Values \\
$\sum\left(\mathrm{X}-\mathrm{M}_{\mathrm{x}}\right)^{2}=\mathrm{SS}_{\mathrm{x}}=0.003$ & $M_{y}:$ Mean of Y Values \\
$X-M_{\mathrm{x}} \& Y-M_{\mathrm{y}}:$ Deviation scores \\
$Y$ Values & $\left(X-M_{x}\right)^{2} \&\left(Y-M_{y}\right)^{2}:$ Deviation Squared \\
$\sum=42.081$ & $\left(X-M_{x}\right)\left(Y-M_{\mathrm{y}}\right):$ Product of Deviation Scores \\
Mean $=2.104$ & \\
$\sum\left(\mathrm{Y}-\mathrm{M}_{\mathrm{y}}\right)^{2}=\mathrm{SS}_{\mathrm{y}}=500.231$ & \\
$X$ and $Y$ Combined & \\
$N=20$ & \\
$\sum\left(\mathrm{X}-\mathrm{M}_{\mathrm{x}}\right)\left(\mathrm{Y}-\mathrm{M}_{\mathrm{y}}\right)=-0.35$ & \\
$R$ Calculation & \\
$\mathrm{r}=\sum\left(\left(\mathrm{X}-\mathrm{M}_{\mathrm{y}}\right)\left(\mathrm{Y}-\mathrm{M}_{\mathrm{x}}\right)\right) / \sqrt{ }\left(\left(\mathrm{SS}_{\mathrm{x}}\right)\left(\mathrm{SS}_{\mathrm{y}}\right)\right)$ & \\
$\mathrm{r}=-0.35 / \sqrt{ }((0.003)(500.231))=-0.308$ & \\
$M$ Meta Numerics $($ cross-check $)$ & \\
$\mathrm{r}=-0.308$ & \\
\hline
\end{tabular}

The value of $\mathrm{R}$ is -0.308 .

Although technically this is a negative correlation, the relationship between your variables is only weak (the nearer the value is to zero, the weaker the relationship).

The value of $\mathrm{R}^{2}$, the coefficient of determination, is 0.0949 .

\section{Correlation Coefficient (Happiness score/GDP share)}

X Values - Happiness score 2018 (country order according to HDI - best 20 in 2018)

Y Values - GDP share 2018 (World Happiness Report, 2018) (Nominal (billions of \$) - corresponding countries (List of Countries by GDP (Nominal), 2018)

\begin{tabular}{c|c}
\hline X Values & Y Values \\
\hline 7.594 & 0.331 \\
7.487 & 0.507 \\
7.272 & 0.423 \\
6.977 & 0.0333 \\
6.965 & 0.848 \\
7.495 & 1.08 \\
6.441 & 2.06 \\
7.314 & 0.252 \\
6.343 & 0.687 \\
7.441 & 1.71 \\
7.555 & 0.427 \\
7.328 & 0.546 \\
6.886 & 0.0700
\end{tabular}




\begin{tabular}{l|c}
6.814 & 0.440 \\
7.632 & 4.81 \\
7.324 & 0.643 \\
6.927 & 0.0828 \\
5.915 & 23.3 \\
7.139 & 3.36 \\
6.910 & 0.471 \\
\hline
\end{tabular}

\begin{tabular}{|c|c|c|c|c|}
\hline $\mathrm{X}-\mathrm{M}_{\mathrm{x}}$ & $\mathrm{Y}-\mathrm{M}_{\mathrm{y}}$ & $\left(\mathrm{X}-\mathrm{M}_{\mathrm{x}}\right)^{2}$ & $\left(\mathrm{Y}-\mathrm{M}_{\mathrm{y}}\right)^{2}$ & $\left(\mathrm{X}-\mathrm{M}_{\mathrm{x}}\right)\left(\mathrm{Y}-\mathrm{M}_{\mathrm{y}}\right)$ \\
\hline 0.506 & -1.773 & 0.256 & 3.144 & -0.897 \\
0.399 & -1.597 & 0.159 & 2.551 & -0.637 \\
0.184 & -1.681 & 0.034 & 2.826 & -0.309 \\
-0.111 & -2.071 & 0.012 & 4.288 & 0.230 \\
-0.123 & -1.256 & 0.015 & 1.578 & 0.154 \\
0.407 & -1.024 & 0.166 & 1.049 & -0.417 \\
-0.647 & -0.044 & 0.419 & 0.002 & 0.029 \\
0.226 & -1.852 & 0.051 & 3.430 & -0.419 \\
-0.745 & -1.417 & 0.555 & 2.008 & 1.056 \\
0.353 & -0.394 & 0.125 & 0.155 & -0.139 \\
0.467 & -1.677 & 0.218 & 2.813 & -0.783 \\
0.240 & -1.558 & 0.058 & 2.428 & -0.374 \\
-0.202 & -2.034 & 0.041 & 4.137 & 0.411 \\
-0.274 & -1.664 & 0.075 & 2.769 & 0.456 \\
0.544 & 2.706 & 0.296 & 7.322 & 1.472 \\
0.236 & -1.461 & 0.056 & 2.135 & -0.345 \\
-0.161 & -2.021 & 0.026 & 4.085 & 0.325 \\
-1.173 & 21.196 & 1.376 & 449.268 & -24.862 \\
0.051 & 1.256 & 0.003 & 1.577 & 0.064 \\
-0.178 & -1.633 & 0.032 & 2.667 & 0.291 \\
$\mathrm{Mx}: 7.088$ & $\mathrm{My}: 2.104$ & Sum: 3.971 & Sum: 500.231 & Sum: -24.695 \\
\hline
\end{tabular}

\begin{tabular}{|c|c|}
\hline $\begin{array}{l}\text { Result Details \& Calculation } \\
X \text { Values } \\
\sum=141.759 \\
\text { Mean }=7.088 \\
\sum\left(\mathrm{X}-\mathrm{M}_{\mathrm{x}}\right)^{2}=\mathrm{SS}_{\mathrm{x}}=3.971 \\
Y \text { Values } \\
\sum=42.081 \\
\text { Mean }=2.104 \\
\sum\left(\mathrm{Y}-\mathrm{M}_{\mathrm{y}}\right)^{2}=\mathrm{SS}_{\mathrm{y}}=500.231 \\
X \text { and } Y \text { Combined } \\
N=20 \\
\sum\left(\mathrm{X}-\mathrm{M}_{\mathrm{x}}\right)\left(\mathrm{Y}-\mathrm{M}_{\mathrm{y}}\right)=-24.695 \\
R \text { Calculation } \\
\mathrm{r}=\sum\left(\left(\mathrm{X}-\mathrm{M}_{\mathrm{y}}\right)\left(\mathrm{Y}-\mathrm{M}_{\mathrm{x}}\right)\right) / \sqrt{ }\left(\left(\mathrm{SS}_{\mathrm{x}}\right)\left(\mathrm{SS}_{\mathrm{y}}\right)\right) \\
\mathrm{r}=-24.695 / \sqrt{ }((3.971)(500.231))=-0.5541 \\
\text { Meta Numerics }(\text { cross-check }) \\
\mathrm{r}=-0.5541\end{array}$ & $\begin{array}{l}\text { Key } \\
X: \mathrm{X} \text { Values } \\
Y: \mathrm{Y} \text { Values } \\
M_{x}: \text { Mean of } \mathrm{X} \text { Values } \\
M_{y}: \text { Mean of } \mathrm{Y} \text { Values } \\
X-M_{\mathrm{x}} \& Y-M_{y}: \text { Deviation scores } \\
\left(X-M_{x}\right)^{2} \&\left(Y-M_{y}\right)^{2} \text { : Deviation Squared } \\
\left(X-M_{\chi}\right)\left(Y-M_{y}\right): \text { Product of Deviation Scores }\end{array}$ \\
\hline
\end{tabular}


The value of $\mathrm{R}$ is -0.5541 .

This is a moderate negative correlation, which means there is a tendency for high $\mathrm{X}$ variable scores to go with low Y variable scores (and vice versa).

The value of $\mathrm{R}^{2}$, the coefficient of determination, is 0.307 .

\section{CONCLUDING CONSIDERATIONS}

The discrepancy between growth and development is evident as in living creatures, as well as in social phenomena. The growth and development of the economy is such a complex phenomenon, which in any case stems from the scope of only quantitative and monetary expression of production, that is, it comes out of the framework of observing man only as an economic being and requires a multidisciplinary approach. Such an analysis requires a lot of time and space, as well as an expert team from many areas, and this paper makes a limited analysis of the correlative relationships of the three basic indicators that measure growth and development in countries around the world. Limited in terms of a sample of only the top 20 countries, and limited in terms of applying only one indicator of correlation between the indicators which are analyzed. However, the results obtained show a weak positive correlation in the first relationship, and from a mild negative to moderate negative correlation in the other two relationships. This logically leads to the conclusion that economic growth does not always mean human development, prosperity and a sense of well-being or confirmation of the old truth that more money does not mean more happiness (at least not always). Possible errors in the used methodology are out of the scope of this paper, they are beyond the spatial opportunities of this paper. A more comprehensive analysis of this issue requires multidimensional analysis and involvement of many experts from different fields (economics, mathematics, statistics, psychology, sociology, etc.). But in any case, the proposed analysis imposes a need for further analysis of the negative correlations that appear.

\section{REFERENCES}

Callen, T., Gross Domestic Product: An Economy's All, IMF, FINANCE \& DEVELOPMENT, Retrieved July 29, 2017, from https://www.imf.org/external/pubs/ft/fandd/basics/gdp.htm

Dawson, G., (2006), Economics and Economic Change, FT / ISBN 0-273-69351-4: Prentice Hall. International Monetary Fund. World Economic Outlook (April - 2018). Retrieved May 6, 2018, from https://www.imf.org/en/Publications/WEO/Issues/2018/03/20/world-economic-outlook-april-2018

Lepenies, P. \& Gaines, J. (2016). The Power of a Single Number: A Political History of GDP, Columbia University Press, ISBN 978-0-231-17510-4, New York, Retrieved from http://www. jstor.org/stable/10.7312/lepe17510

List of Countries by GDP (Nominal). (2018). Retrieved from http://statisticstimes.com/economy/ countries-by-gdp.php

Mojsoski, V. \& Karadjova, V. (2002). Applied economy, ISBN 9989-767-04-01: CNIR-FTU Ohrid.

OECD, SNA 1.128 and 2.173-2.174. Retrieved from https:/stats.oecd.org/glossary/detail.as$\mathrm{p}$ ? ID $=1163$

UNDP. (2010). The Human Development concept, Retrieved July 29, 2011

UNDP. (2018). Human Development Reports, Retrieved from http://hdr.undp.org/en/content/human-development-index-hdi

UNDP. (2018). Latest Human Development Index (HDI) Ranking, Retrieved from http://hdr.undp. org/en/2018-update

World Happiness Report. (2018). Retrieved from http://worldhappiness.report/ed/2018 